\title{
Effect of Noncanonical Amino Acids on Protein-Carbohydrate Interactions: Structure, Dynamics, and Carbohydrate Affinity of a Lectin Engineered with Fluorinated Tryptophan Analogs
}

\author{
Felix Tobola, ${ }^{\dagger, \ddagger}$ Mickael Lelimousin, ${ }^{\S}$ Annabelle Varrot, ${ }^{\S}$ Emilie Gillon, ${ }^{\S}$ Barbara Darnhofer, ${ }^{\dagger, \|, \perp}$
}

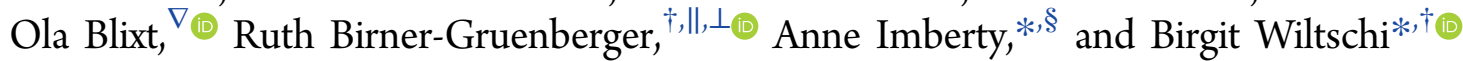

\author{
${ }^{\dagger}$ Austrian Centre of Industrial Biotechnology, Petersgasse 14, 8010 Graz, Austria \\ ${ }^{\ddagger}$ Institute of Molecular Biotechnology, Graz University of Technology, Petersgasse 14, 8010 Graz, Austria \\ ${ }^{\S}$ Univ. Grenoble Alpes, CNRS, CERMAV, 38000 Grenoble, France \\ "Research Unit of Functional Proteomics and Metabolomics, Institute of Pathology, Medical University of Graz, Stiftingtalstrasse 24, \\ 8010 Graz, Austria \\ ${ }^{\perp}$ Omics Center Graz, BioTechMed-Graz, Stiftingtalstrasse 24, 8010 Graz, Austria \\ ${ }^{\nabla}$ Department of Chemistry, Chemical Biology, University of Copenhagen, Thorvaldsensvej 40, 1871 Frederiksberg C, Denmark
}

\section{Supporting Information}

ABSTRACT: Protein-carbohydrate interactions play crucial roles in biology. Understanding and modifying these interactions is of major interest for fighting many diseases. We took a synthetic biology approach and incorporated noncanonical amino acids into a bacterial lectin to modulate its interactions with carbohydrates. We focused on tryptophan, which is prevalent in carbohydrate binding sites. The exchange of the tryptophan residues with analogs fluorinated at different positions resulted in three distinctly fluorinated variants of the lectin from Ralstonia solanacearum. We observed differences in stability and affinity toward fucosylated glycans and rationalized them by X-ray and modeling studies. While fluorination decreased the aromaticity of the indole ring and, therefore, the strength of carbohydrate-aromatic interactions, additional weak hydrogen bonds were formed between fluorine and the ligand hydroxyl groups. Our approach opens new possibilities to engineer carbohydrate receptors.

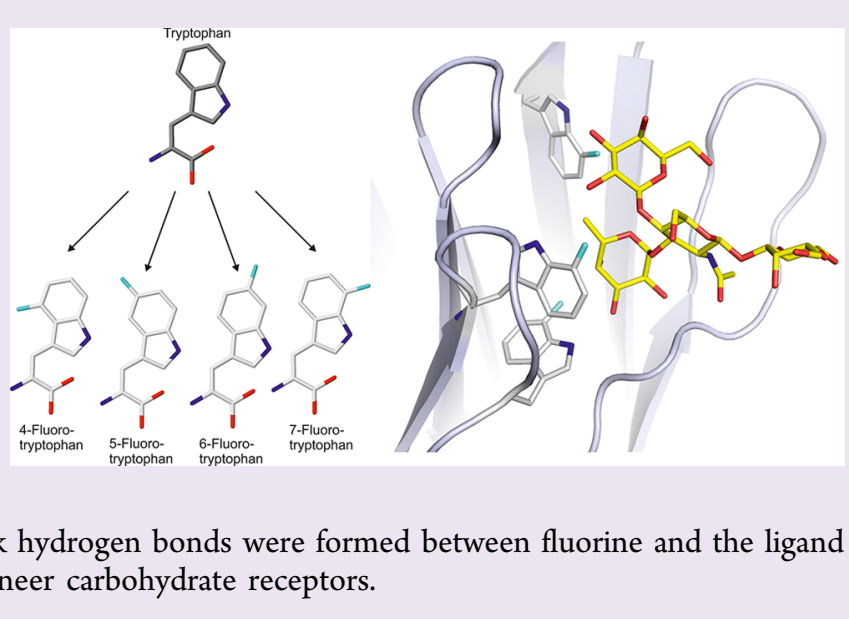

3-fold reduced affinity for the sugar with a variant containing 5fluorotryptophan in its ligand binding site compared to the unlabeled receptor. Similarly, fluorination of phenylalanine and tyrosine of the small antibiotic peptide AcAMP2 lowered its affinity for chitin trisaccharide. ${ }^{16}$

Ralstonia solanacearum lectin (RSL) is a carbohydrate binding protein with unusually strong affinity for fucose and specificity for fucosylated oligosaccharides from plants and animals. ${ }^{17}$ RSL is a homotrimer that forms a six-bladed $\beta$-propeller fold. It presents six carbohydrate binding sites, which are either intra- or intermonomeric (Figure 1a), and nonetheless are structurally very similar. ${ }^{17}$ Each RSL monomer contains seven Trp residues, six of which are directly involved in carbohydrate binding (Supporting Information, Table S1). The analysis of the RSL structure combined with modeling revealed the importance of three Trp residues present in the binding site. One makes

Received: April 24, 2018

Accepted: May 29, 2018

Published: May 29, 2018 

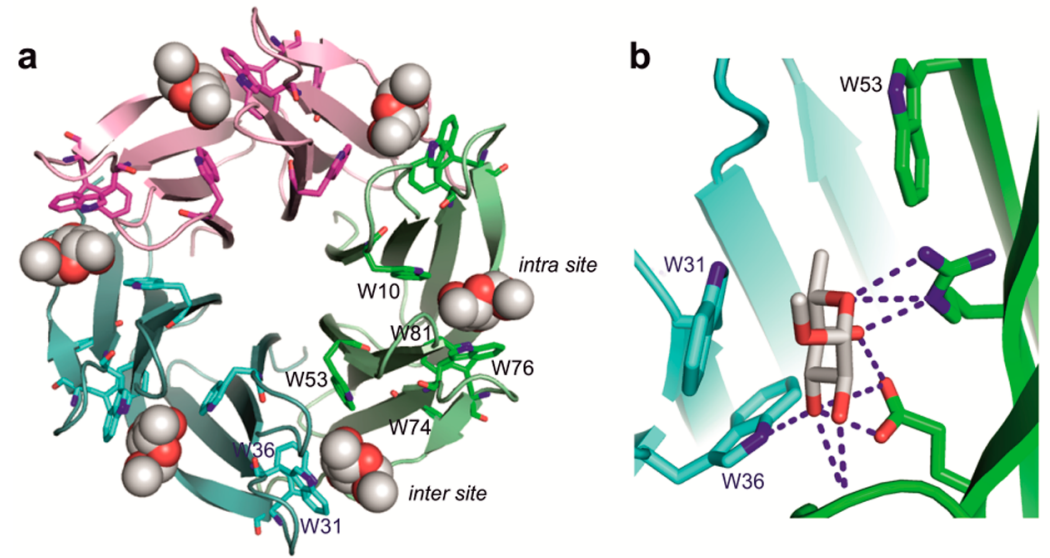

C

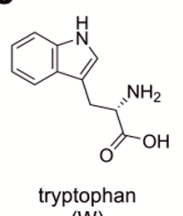

(W)

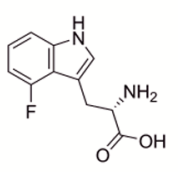

4-fluorotryptophan $(4 \mathrm{FW})$

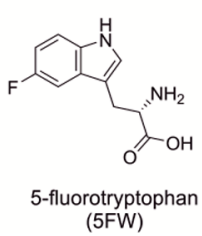

$(5 \mathrm{FW})$
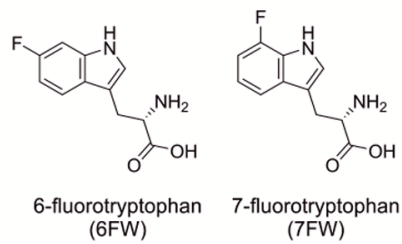

Figure 1. (a) Structure of RSL (pdb 2BT9). The three monomers are colored in magenta, green, and cyan; the bound $\alpha$ MeFuc is represented as spheres. (b) The intermonomeric binding site with three important Trp residues: W31, W36, and W53 (structurally equivalent to W76, W81, and W10 in the intramonomeric site). (c) Structures of L-tryptophan and the fluorinated L-analogs used in this study.

hydrophobic contact with the sugar methyl group; another is involved in hydrogen bonding (Figure 1b). The third is responsible for a stacking interaction with the fucose residue and defines the specificity for this sugar. ${ }^{18,19}$ Such carbohydratearomatic interactions are frequent ${ }^{20,21}$ with a 9-fold prevalence of Trp in the carbohydrate binding site. ${ }^{21}$ Recently, Trp was also demonstrated to have a crucial role in inducing a large conformational change of a fucosylated trisaccharide in the RSL binding site. ${ }^{22}$

RSL appears as an excellent model protein to study the effect of tryptophan fluorination on carbohydrate recognition. Here, we incorporated four fluorinated Trp analogs (Figure 1c) into RSL to examine the effect on the protein stability and affinity toward mono- and oligosaccharides. We report the first crystal structures of fluorinated lectins and elucidate the molecular details of their interaction with ligands. After appropriate parametrization, molecular modeling gave access to the dynamics of the modified proteins and demonstrated the predictive power of modeling ncAA incorporation.

\section{RESULTS AND DISCUSSION}

Lectin Production and Physicochemical Characterization. We employed the supplementation of a tryptophan auxotrophic Escherichia coli strain with four tryptophan analogs (FWs, Figure 1c) for their residue-specific incorporation ${ }^{23}$ into RSL. Since the tryptophan analogs are not commercially available, we fed our cells with indole analogs to convert these to tryptophan analogs ${ }^{24-27}$ in situ by the host tryptophan synthase (reviewed by Phillips ${ }^{28}$ ). The procedure resulted in titers of purified synthetic variants in the range of 35-60 mg lyophilized protein per liter of cell culture, compared to $100 \mathrm{mg}$ $\mathrm{L}^{-1}$ cell culture for the unmodified parent protein. Interestingly, the incorporation of 6FW drove RSL into insolubility, while all other fluorinated RSL variants remained soluble (Figure S1). Efficient labeling of RSL with FWs was confirmed by mass spectrometry (Figure S2). The majority of the proteins ( $85 \%$ of $\mathrm{RSL}[4 \mathrm{FW}], 86 \%$ of RSL[5FW] and $84 \%$ of RSL[7FW]) showed quantitative replacement of Trp by the analogs, and only in a minor fraction (14-16\%) the exchange was incomplete (Table S2). By assuming a random distribution of the unlabeled residues over the seven positions, one would thus expect a labeling efficiency of $97 \%(\mathrm{RSL}[7 \mathrm{FW}]$ ) to $98 \%$ (RSL[4FW] and RSL $[5 F W]$ ) per site. To test the individual sites for labeling with the fluorinated Trp analogs, we subjected the fluorinated variants and the wild-type RSL proteins to different enzymatic digests to ensure nearly complete sequence coverage. Nano-LCtandem mass spectrometry analysis showed that four Trp residues and their respective fluoro-analogs could be relatively quantified (W10, W31, W53, W74) because they were covered in well ionizing peptides with a single Trp in their sequence (Figure S3). Only minimal residual unlabeled Trp was found in the labeled protein analogs at these four positions $(<3 \%$ of wildtype), which matches the proportion expected by a random distribution.

We analyzed the physico- and biochemical properties of the synthetic RSL variants. Several reports in the literature indicate that the incorporation of fluorinated ncAAs results in increased protein stability. ${ }^{29-31}$ We compared the thermostability of the variants to the parent protein using differential scanning fluorimetry (DSF) and differential scanning calorimetry (DSC). Indeed, in the presence of D-mannose, the 5FWcontaining variant showed a slightly increased melting temperature in comparison to the parent protein $\left(T_{\mathrm{m}}=90^{\circ} \mathrm{C} v \mathrm{~s} T_{\mathrm{m}}=88\right.$ ${ }^{\circ} \mathrm{C}$; Figure S4a). In contrast, the incorporation of 4 - and $7 \mathrm{FW}$ clearly decreased the melting temperatures to 79 and $72{ }^{\circ} \mathrm{C}$, respectively. The same effects were observed by DSC measurements in the presence of the high-affinity ligand methyl $\alpha$-Lfucopyranoside $(\alpha \mathrm{MeFuc})^{17}$ (Figure S4b). Since the interaction of the RSL variants with the high-affinity ligand exceeded the range of DSF, we used DSC for the analysis. The results exemplify the remarkably pronounced effect of the position of the fluorine atom in the indole ring on protein stability. As shown in Figure 1, Trp residues are involved in interblade contacts, and 

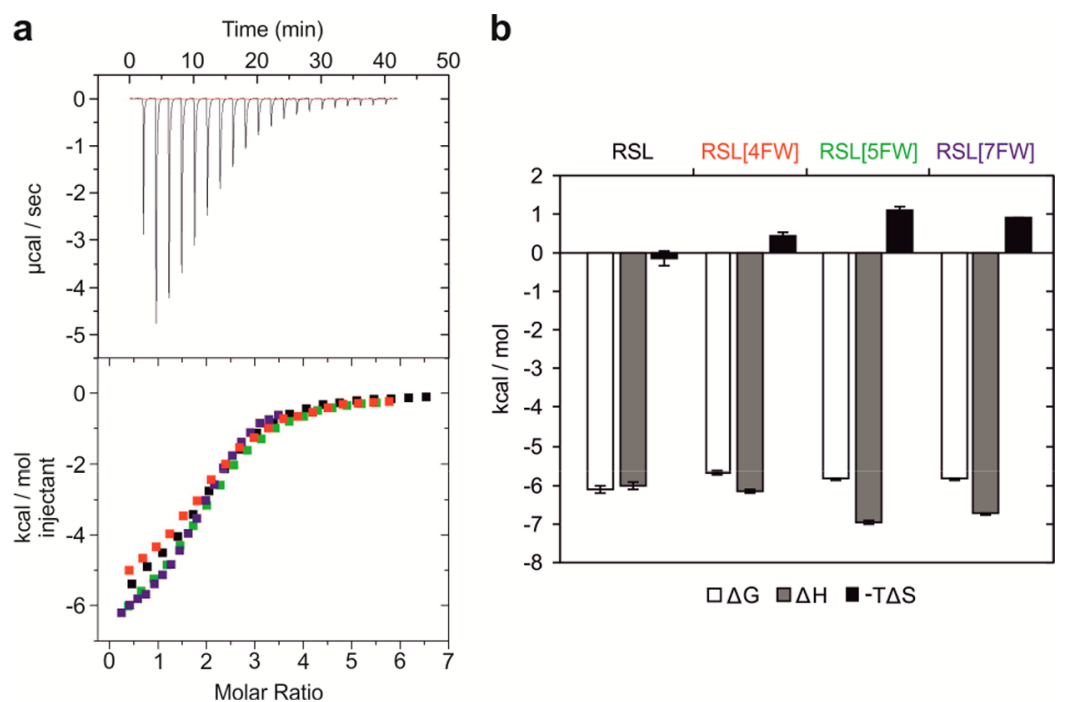

Figure 2. ITC experiment of RSL and fluorinated RSL binding to the tetrasaccharide $\mathrm{Le}^{\mathrm{X}}$. (a) Thermogram (top) of the injection of Le ${ }^{\mathrm{X}}$ aliquots to RSL in solution and corresponding integrated peaks (bottom) for RSL and the variants. (b) The thermodynamic contributions were derived from curve fitting. Entropy cost, $-T \Delta S$; enthalpy contribution, $\Delta H$; free energy of binding, $\Delta G$.

alteration of their structure may indeed affect the folding $(6 \mathrm{FW})$ or modify the protein's stability.

Affinity for Different Ligands. Given the prominent position of the fluorine in the ligand binding site of the synthetic RSL variants, we hypothesized that the variants could show subtle affinity differences for different sugar ligands. Therefore, we analyzed the affinity toward $\alpha \mathrm{MeFuc}$ and two tetrasaccharides, blood group $\mathrm{H}$ type 2 antigen (HType2, Fuc $\alpha 1-2 \mathrm{Gal} \beta 1-$ $4 \mathrm{GlcNAc} \beta 1-3 \mathrm{Gal})$ and lewis $\mathrm{X}\left(\mathrm{Le}^{\mathrm{X}}, \mathrm{Gal} \beta 1-4[\mathrm{Fuc} \alpha 1-3]\right.$ $\mathrm{GlcNAc} \beta 1-3 \mathrm{Gal}$ ) by isothermal titration calorimetry (ITC, Figure S5, Table S3). A dissociation constant, $K_{\mathrm{d}}$ of $1.21 \pm 0.04$ $\mu \mathrm{M}$ was measured for RSL interacting with $\alpha \mathrm{MeFuc}$, which is in agreement with previous reports. ${ }^{17} \mathrm{RSL}[5 \mathrm{FW}]$ and RSL[7FW] behaved similarly, with $K_{d}$ values of $0.889 \pm 0.004$ and $1.11 \pm$ $0.02 \mu \mathrm{M}$, respectively, while $\mathrm{RSL}[4 \mathrm{FW}]$ displayed a slightly lower affinity $\left(K_{\mathrm{d}}=1.73 \pm 0.41 \mu \mathrm{M}\right)$. We only observed minor differences in affinity toward HType2. They varied from $4.35 \pm$ $0.35 \mu \mathrm{M}$ for RSL[7FW] to $8.18 \pm 0.99 \mu \mathrm{M}$ for $\mathrm{RSL}[4 \mathrm{FW}]$. $\mathrm{RSL}[4 \mathrm{FW}]$ displayed a lower affinity toward $\mathrm{Le}^{\mathrm{X}}\left(K_{\mathrm{d}}=67.8 \pm 6.8\right.$ $\mu \mathrm{M})$ than RSL $\left(K_{\mathrm{d}}=32.5 \pm 4.9 \mu \mathrm{M}\right)$ and the other two variants (RSL[4FW], $K_{\mathrm{d}}=52.4 \pm 2.6 \mu \mathrm{M}$; RSL[7FW], $K_{\mathrm{d}}=52.1 \pm 0.8$ $\mu \mathrm{M})$. While RSL bound $\mathrm{Le}^{\mathrm{X}}$ with no entropy cost, both $\mathrm{RSL}[5 \mathrm{FW}]$ and $\mathrm{RSL}[7 \mathrm{FW}]$ displayed a stronger enthalpy contribution and some entropy cost for binding $(\Delta H,-T \Delta S$; Figure 2). Le $\mathrm{x}^{\mathrm{X}}$ was therefore selected for the structural study to determine the molecular basis of the thermodynamic behavior.

Structural Analysis. The three fluoro-RSL proteins were cocrystallized with the $\mathrm{Le}^{\mathrm{X}}$ tetrasaccharide using the vapor diffusion method and yielded diamond-shaped crystals diffracting to high resolution ( 1.15 to $1.35 \AA$ ). All structures belonged to the F23 space group with two independent monomers in the asymmetric unit (Table S4, PDB ID 5O7W, 5O7V, and 5O7U). The presence of the 3-fold axis resulted in the generation of two trimers (A and $\mathrm{B}$ ), which are similar to the RSL native structure (2BT9) with RMSD lower than $0.2 \AA$ (Figure 3a).

The electron density of the Trp residues in the binding sites clearly indicated the presence of the fluorine at each expected position (Figures S6-S8). The effect of fluorination on the conformation of the Trp side chains is very limited, except for Trp76 in the 4FW variant. In chain A of the RSL[4FW] structure
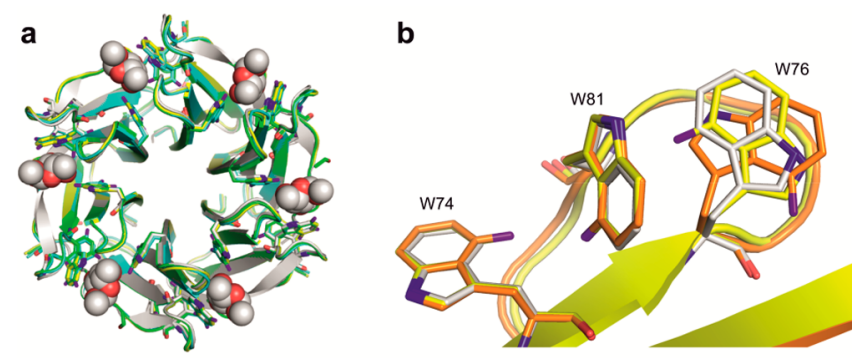

Figure 3. (a) Superimposition of the crystal structure of the RSL/ $\alpha \mathrm{MeFuc}$ complex (white; pdb 2BT9) with the structures of RSL[4FW] (yellow; pdb 5O7W), RSL[5FW] (cyan; pdb 5O7V), and RSL[7FW] (green; pdb 5O7U). (b) Superimposition of loop 76-82 from wt-RSL (white), and chain A (yellow) and chain B (orange) of RSL[4FW]. Fluorine atoms are colored in purple.

(Figure 3b, yellow), the indole ring of Trp76 is slightly pushed back, while it undergoes a $180^{\circ}$ rotation around the $\mathrm{C} \beta-\mathrm{C} \gamma$ bond in chain $\mathrm{B}$ (Figure $3 \mathrm{~b}$, orange), orienting the fluorine to the opposite side. Clearly, fluorination at this position results in a steric repulsion with the neighboring $\operatorname{Trp} 81$, which induces the rearrangement.

We clearly observed the electron density of the carbohydrate ligand in all structures (Figure S6-S8). Similar to previous observations in the RSL/Le ${ }^{\mathrm{X}}$ complex, ${ }^{22}$ the $\mathrm{Le}^{\mathrm{X}}$ adopted open conformations (Table S5) that were very different from those observed in solution. ${ }^{32}$ The conformational behavior of $\mathrm{Le}^{\mathrm{X}}$ in RSL was comprehensively described in previous work, ${ }^{32}$ and we focus here on the contacts between the fluorinated Trp residues and the oligosaccharide ligand. For the sake of clarity, the description of structures and models below will be centered on the intermonomeric site that does not present significant variations as the intramonomeric site does. Due to the orientation of the indole ring of the Trp residues (Figure 4a), we observed no direct contacts between the fluorine atoms and the ligand in the complex with $\mathrm{RSL}[4 \mathrm{FW}]$. The fluorine on Trp31 of RSL[5FW] had limited contact $(\sim 4 \AA)$ to the C3 of fucose. Nevertheless, $\mathrm{Le}^{\mathrm{X}}$ made several contacts within RSL[7FW] (Figure 4b). The fluorine atom of Trp36 was close to the $\mathrm{O} 3$ and $\mathrm{O} 4$ hydroxyls of fucose with an $\mathrm{F} \cdots \mathrm{O}$ distance of 3.3 and 

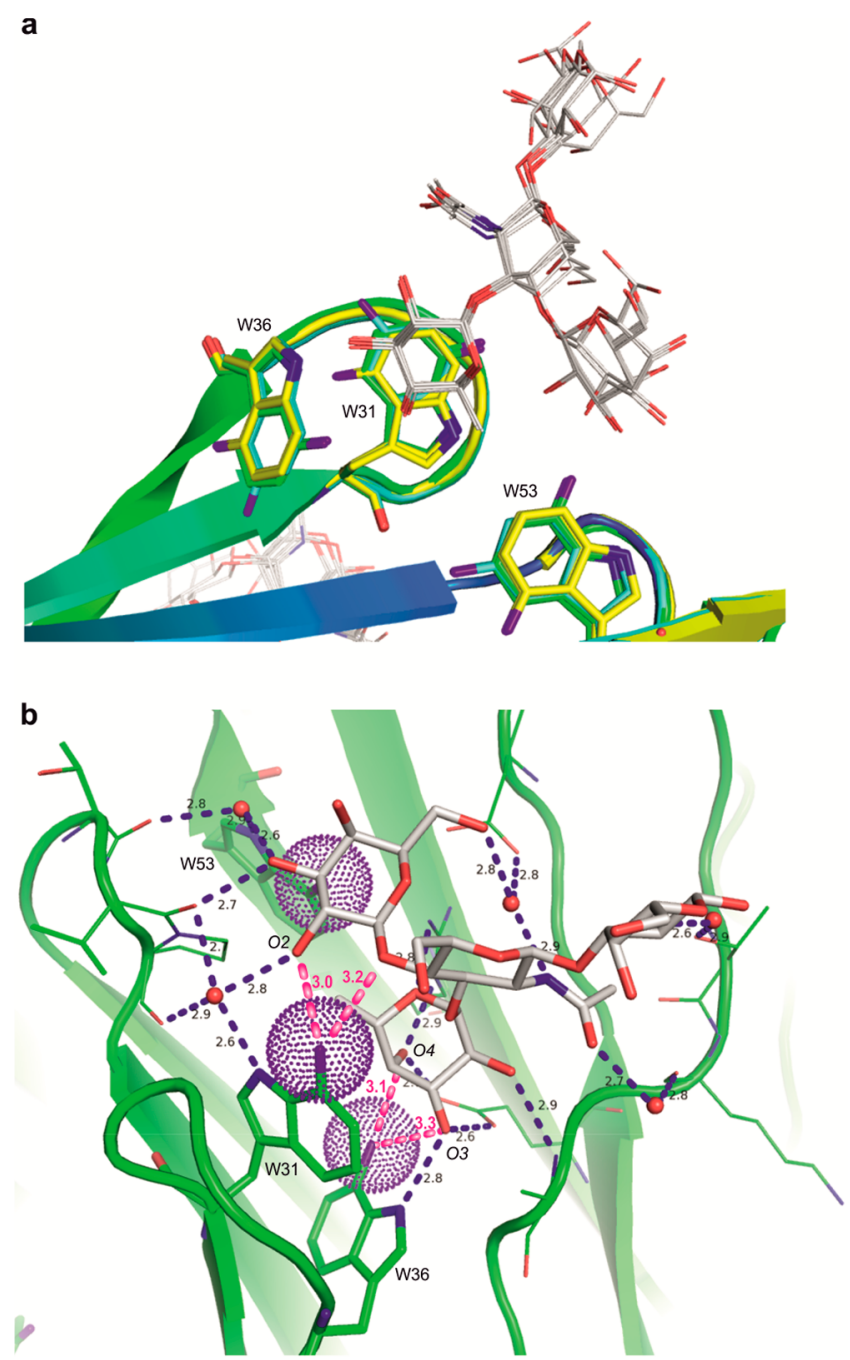

Figure 4. (a) Superimposition of the six intermonomeric binding sites (chains A and B of the three RSL variants) complexed with the $\mathrm{Le}^{\mathrm{X}}$ tetrasaccharide. Color coding as in Figure 3a. (b) Close-up of the intermonomeric binding site of RSL[7FW] (chain B). The network of hydrogen bonds is displayed as dashed blue lines, and contacts with the fluorine atoms are in magenta.

3.1 A, respectively. The fluorine of Trp31 was in close proximity to $\mathrm{O} 2$ of galactose and to $\mathrm{O} 4$ of GlcNAc (3.0 and $3.2 \AA$ ). Such distances are indicative of favorable contacts, and indeed, fluorine atoms are considered as weak acceptors of hydrogen bonds. ${ }^{33,34}$ Fluorination is expected to induce a large modification of the $\pi$ electron density on the indole ring, ${ }^{14}$ so the effect on the affinity may be more complex than the observed weak hydrogen bonds.
Modeling of FW-Ligand Interactions. We performed molecular modeling to dissect the interaction between residues Trp31 and Trp36 that are involved in stacking with fucose and in hydrogen bonding, respectively. Parameterization was necessary to include F-Trp in the model. Atomic charges (Table S6) and other parameters were obtained by quantum chemical calculations and were included in Amber Tools to prepare the topology files of the different complexes. The monosaccharide $\alpha \mathrm{MeFuc}$ was selected as the ligand to avoid the superimposition of the interaction analysis with conformational effects. Each RSL variant complexed with $\alpha \mathrm{MeFuc}$ was submitted to a molecular dynamics simulation of $500 \mathrm{~ns}$ that was used for calculating the interaction energy and its decomposition per residue. ${ }^{35}$

All modeled complexes were very stable, and the average structures of the binding sites were similar to the X-ray structures (Figure S9). The calculated energies of interaction (Table 1) predicted that the parent protein and $\mathrm{RSL}[7 \mathrm{FW}]$ would have a stronger affinity for $\alpha \mathrm{MeFuc}$ than the other variants. This is partially in agreement with experimental ITC data, where RSL[4FW] showed the lowest affinity for $\alpha \mathrm{MeFuc}$ (Figure S5).

A detailed analysis of the influence of the fluorination on the two Trp residues closer to fucose, that is, $\operatorname{Trp} 36$ and $\operatorname{Trp} 31$, demonstrated opposite effects: The binding energy of Trp31 that stacks on fucose is weakened by fluorination. The alteration of the indole charge distribution by fluorine deactivates the aromaticity as previously described for a fluorinated derivative of phenylalanine. ${ }^{16}$ In contrast, the energy of interaction of Trp36 that establishes an $\mathrm{NH}$... O hydrogen bond with the $\mathrm{O} 3$ of fucose is not decreased in the variants compared to the parent RSL (Table 1). In the case of RSL[7FW], the energy of interaction is even increased, which is in agreement with the formation of a fluorine-based hydrogen bond. A closer analysis of the molecular dynamics trajectories indicates that this variant, which shows direct contact between the fluorine atom and the ligand, presents a very unique behavior of fucose in the binding site (Figure 5). While the average structure is similar to the one observed by X-ray, rapid fluctuation in the orientation of fucose creates a sporadic strong hydrogen bond between fluorine and HO4 (distance F...H shorter than $2 \AA$ ), which competes with the hydrogen bond between $\mathrm{HO} 4$ and Glu73.OE1 that is observed in all crystal structures. The rapid change of orientation of fucose is also correlated with a partial loss of stacking with Trp31. The average contacts of fucose in the binding site are not significantly affected (Table 1), but the stability of the complex is lower as indicated by larger deviation in hydrogen bond distances in the RSL[7FW] variant.

Differences in Specificity. Since the Trp residues can interact with other oligosaccharides in addition to the fucose residue, we assessed the specificity of the synthetic lectin variants

Table 1. Interaction Energies and Average Distances Measured with Molecular Dynamics Simulations ${ }^{a}$

\begin{tabular}{lllll}
\multicolumn{1}{c}{ MD simulation data } & RSL-wt & RSL[4FW] & RSL[5FW] & RSL[7FW] \\
$\Delta G(\text { TOT })_{\text {calc }}{ }^{b}$ & -11.2 & -10.2 & -10.2 & -11.2 \\
$\left(\Delta G_{\text {exp }}\right)^{c}$ & $(-8.1)$ & $(-7.9)$ & $(-8.3)$ & $(-8.1)$ \\
$\Delta G(\text { Trp31 })_{\text {calc }}$ & -5.0 & -4.4 & -4.7 & -4.4 \\
$\Delta G(\text { Trp36 })_{\text {calc }}$ & -3.5 & -3.6 & -3.6 & -3.8 \\
$d(\mathrm{H} 5 \cdots \text { Trp31.CZ2 })^{d}$ & $2.84 \pm 0.25$ & $2.94 \pm 0.32$ & $2.85 \pm 0.27$ & $2.93 \pm 0.29$ \\
$d(\mathrm{O} 3 \cdots \text { Trp36.NHE1 })^{d}$ & $1.95 \pm 0.14$ & $1.95 \pm 0.14$ & $1.95 \pm 0.15$ & $1.92 \pm 0.14$ \\
$d(\mathrm{HO} 4 \cdots \text { Glu73.OE2 })^{d}$ & $1.80 \pm 0.19$ & $1.78 \pm 0.17$ & $1.78 \pm 0.18$ & $1.94 \pm 0.32$
\end{tabular}

${ }^{a}$ All energies are in $\mathrm{kcal} \mathrm{mol}^{-1}$. ${ }^{b}$ Calculated binding free energies. ${ }^{c}$ Data measured by ITC in this work. ${ }^{d}$ Distances in $\AA$; time-averaged values and standard deviations were computed over all binding sites of each trimer. 
a

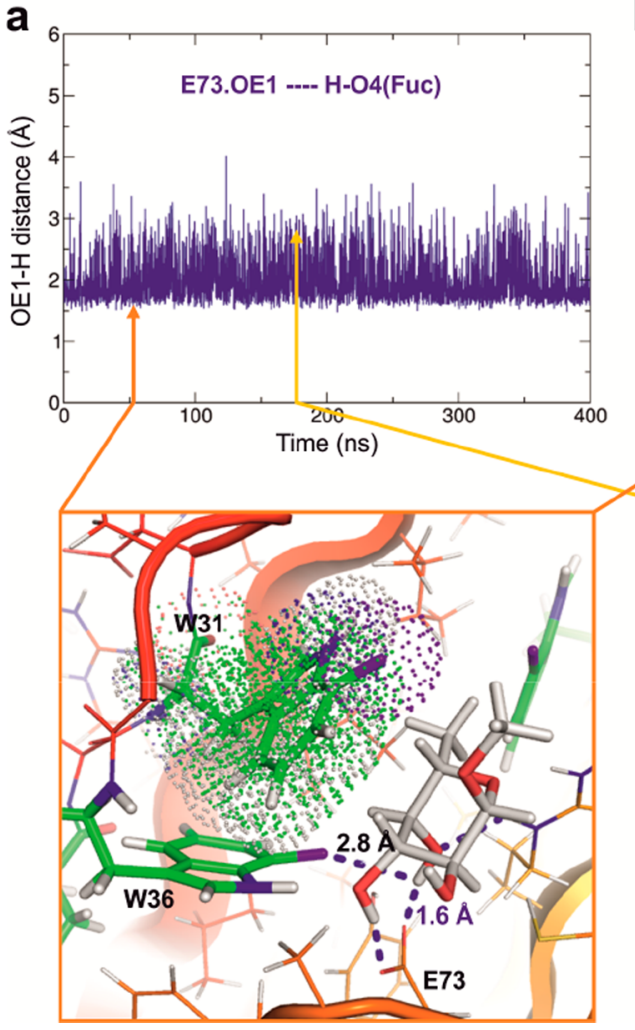

b

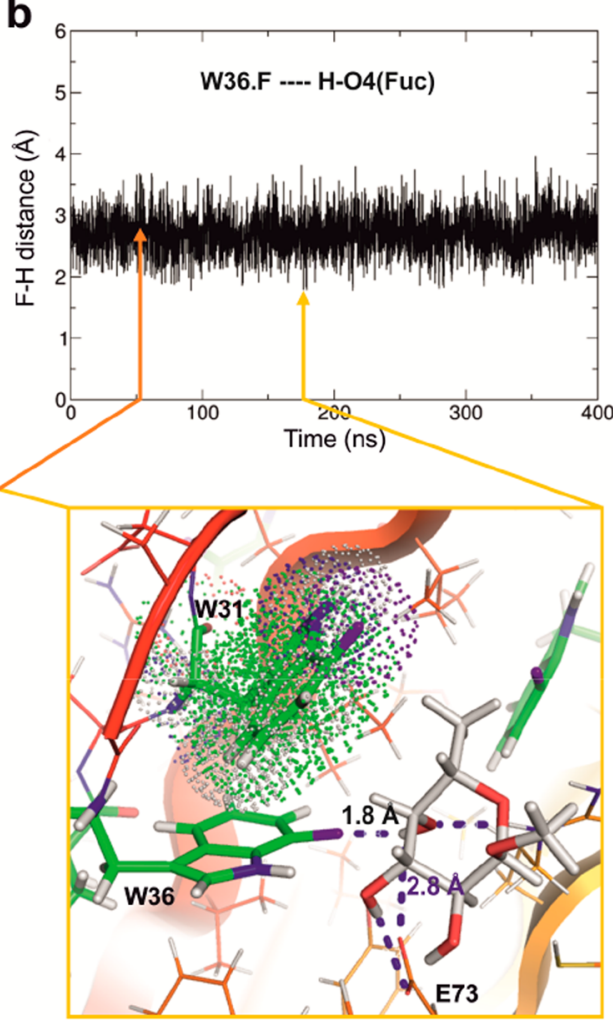

Figure 5. Instability of the hydrogen bond network involving the Fuc-HO4 hydroxyl group in RSL[7FW]. History of distances for competing hydrogen bonds between HO4 and either Trp36.F or Glu73.OE1, and snapshots demonstrating the occurrence of different orientations of fucose in the binding site, which results in alternative hydrogen bond networks. Arrows indicate the position of the two snapshots in the trajectories.

for $>300$ carbohydrates via a previously described ${ }^{36}$ glycan microarray. RSL and all variants demonstrated rather similar binding patterns (Figure S10). They bound to all fucosylated oligosaccharides, as described previously for $\mathrm{RSL}^{17}$ and the structurally related BambL. ${ }^{37}$ Nevertheless, a more thorough comparison of the binding pattern to a subset of fucosylated oligosaccharides, that is, the histo-blood group epitopes, revealed some variations as a function of the position of the fluorine atom (Figure S11). While RSL bound more strongly to oligosaccharides of blood group A and B than to blood group $\mathrm{O}(\mathrm{H})$ and Lewis, this tendency was reversed for the fluorinated variants. Particularly RSL[7W] showed weaker binding to blood group B trisaccharide than to other glycans (Figure 6a, B-tri).

The relative change in specificity can be rationalized by manually docking the blood group B trisaccharide into the RSL binding site. We used the structure of the blood group $\mathrm{B}$ trisaccharide, which had been docked into the related BambL, ${ }^{37}$ and superimposed it on the glycan binding site of RSL[7FW]. Evidently, the galactose residue of blood group B trisaccharide comes in close contact to the fluorine atoms of both Trp53 and Trp31 resulting in local steric conflicts (Figure 6b).

\section{CONCLUSIONS}

We present here the first structural characterization of lectins containing fluorinated tryptophan residues and their interaction with carbohydrate ligands. The global fluorination of the Trp residues moderately affected the glycan affinity, and it changed the specificity for blood group glycans. The structural analysis and the free energy decomposition by molecular dynamics calculations pointed out that fluorination may induce different effects. The stacking effect is partially lost, due to the deactivation

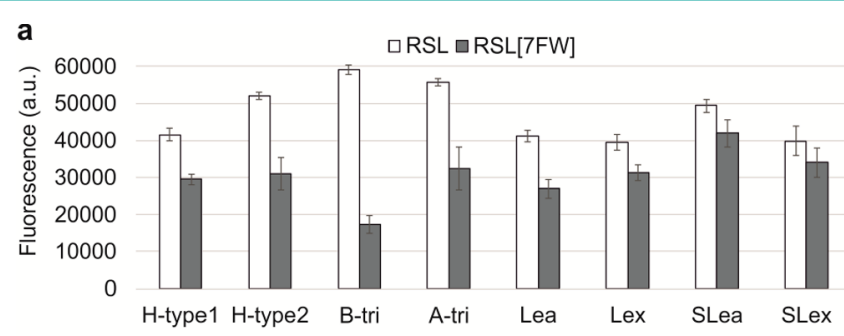

b

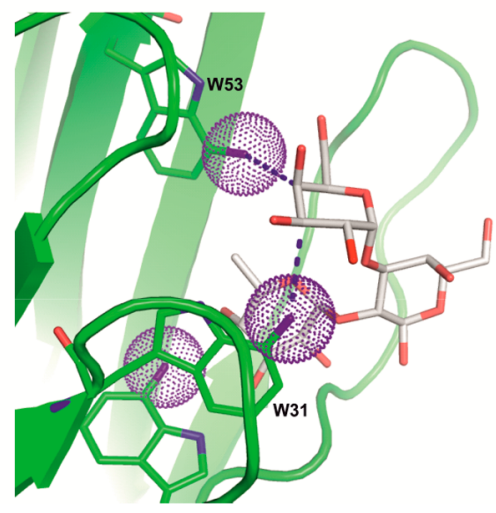

Figure 6. (a) Comparison of the blood group oligosaccharide-binding specificity of RSL and RSL[7FW]. Full names and chemical structures of the glycans are shown in Figure S11. (b) Docking of blood group B trisaccharide into the intermonomeric site of RSL[7FW] reveals nonfavorable short contacts between the fluorine atoms at Trp53 and Trp31 and the $\mathrm{CH}$ groups at positions $\mathrm{C} 3$ and $\mathrm{C} 4$ of galactose.

of the aromaticity. Based on our experiments and calculations, the hydrogen bond property of the $\mathrm{NH}$ group of the indole ring does not seem to be affected by the presence of the neighboring 
fluorine. Of interest for the future design of synthetic proteins with noncanonical amino acids is the possibility to create novel contacts, based on the weak hydrogen bond acceptor character of fluorine and the strong capacity of sugars to be involved in such contacts. Either the introduction of additional hydrogen bonds via the fluorine or the weakening of the stacking interaction with the ligand might be exploited. Here, we used a lectin in which several Trp residues participate in glycan binding and their global exchange for fluorinated derivatives leads to effects that interfere with each other. The site-specific incorporation of Trp analogs could be beneficial for a more surgical lectin-carbohydrate interaction analysis. Yet at the moment, this approach is limited to a small set of Trp analogs excluding fluorinated derivatives. ${ }^{38}$ The approach described here could be used in the future for incorporation of fluorinated Trp analogs into lectins or other carbohydrate-binding proteins that involve a single Trp residue in the glycan binding. This could be a promising compromise until the advent of more versatile site-specific incorporation systems for these analogs. Precise insertion of fluorination in engineered proteins and the exploration of other hydrogen bond accepting groups represent a promising strategy for the conception of novel receptors for glycans.

\section{METHODS}

Protein Expression and Purification. The incorporation of tryptophan analogs into the Ralstonia solanacearum lectin (RSL) was performed in E. coli BWEC47, a tryptophan auxotrophic derivative of strain BL21-Gold (DE3) (Agilent Technologies, Palo Alto, CA), genotype E. coli B F ${ }^{-}$ompT hsdS $\left(\mathrm{r}_{\mathrm{B}}{ }^{-} \mathrm{m}_{\mathrm{B}}{ }^{-}\right) d c m+$ Tet $^{\mathrm{r}} g a l \lambda(\mathrm{DE} 3)$ endA Hte $\Delta \operatorname{trp} C$. The construction of this strain will be described elsewhere.

The amino acid sequence of RSL (PDB 2BS5) was back-translated into a DNA sequence codon optimized for the expression in E. coli and ordered as a gBlock (Integrated DNA Technologies, Coralville, IA). The $r s l$ gene was amplified using primers pBP654 and pBP643 and cloned into the EcoRI/HindIII (Thermo Fisher Scientific, Waltham, MA) digested pQE80L vector (Qiagen, Hilden, Germany) via Gibson assembly $^{39}$ resulting in plasmid pQE80L-RSL. The DNA, primer, and amino acid sequences can be found in Table S1.

The tryptophan auxotrophic E. coli BWEC47 harboring the pQE80LRSL plasmid was grown in M9 medium (47.76 $\mathrm{mM} \mathrm{Na}_{2} \mathrm{HPO}_{4}, 22.04$ $\mathrm{mM} \mathrm{KH}_{2} \mathrm{PO}_{4}, 8.56 \mathrm{mM} \mathrm{NaCl}, 18.69 \mathrm{mM} \mathrm{NH}_{4} \mathrm{Cl}, 22 \mathrm{mM} \alpha$-D-glucose, 1 $\mathrm{mM} \mathrm{MgSO}_{4}, 0.1 \mathrm{mM} \mathrm{CaCl}_{2}, 8.63 \mu \mathrm{M} \mathrm{FeSO}_{4}, 3.55 \mu \mathrm{M} \mathrm{MnSO}_{4}, 2.49 \mu \mathrm{M}$ $\mathrm{AlCl}_{3}, 1.84 \mu \mathrm{M} \mathrm{CoCl}_{2}, 0.42 \mu \mathrm{M} \mathrm{ZnSO}_{4}, 0.5 \mu \mathrm{M} \mathrm{Na}_{2} \mathrm{MoO}_{4}, 0.35 \mu \mathrm{M}$ $\mathrm{CuCl}_{2}, 0.49 \mu \mathrm{M} \mathrm{H}_{3} \mathrm{BO}_{3}$ ) supplemented with $1 \%(\mathrm{w} / \mathrm{v})$ casamino acids (BD Biosciences, San Jose, CA), $47 \mu \mathrm{M}_{\mathrm{L}}$-tryptophan, and $100 \mu \mathrm{g} \mathrm{mL}^{-1}$ ampicillin at $37^{\circ} \mathrm{C}$ and $120 \mathrm{rpm}$ to allow for growth until tryptophan depletion occurred at a cell density of $D_{600} \approx 3$. Subsequently, the cells were incubated for an additional hour to ensure complete depletion of the canonical amino acid, before indole (Sigma-Aldrich, St. Louis, MO) or an indole-analog (4-fluoroindole, Tokyo Chemical Industry Europe, Zwijndrecht, Belgium; 5-, 6-, and 7-fluoroindole, Molekula, Newcastle Upon Tyne, U.K.) was added to a final concentration of $1 \mathrm{mM}$ and protein expression was induced by the addition of $0.5 \mathrm{mM}$ isopropyl $\beta$-Dthiogalactopyranoside (IPTG, Sigma-Aldrich). After expression for $18 \mathrm{~h}$ at $30^{\circ} \mathrm{C}$ and $120 \mathrm{rpm}$, the cells were harvested by centrifugation $(20 \mathrm{~min}$ at $8000 \mathrm{~g}$ and $\left.4{ }^{\circ} \mathrm{C}\right)$. The pellet was resuspended in lysis buffer $(20 \mathrm{mM}$

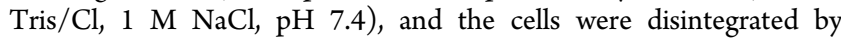
sonication. Cell-free extract was prepared by centrifugation ( $50 \mathrm{~min}$ at $20000 \mathrm{~g}$ and $4{ }^{\circ} \mathrm{C}$ ) and loaded onto a mannose-agarose column (Mannose Separapore 4B, BioWorld, Dublin, OH). Unbound protein was removed by washing with washing buffer $(20 \mathrm{mM}$ Tris/Cl, $100 \mathrm{mM}$ $\mathrm{NaCl}, \mathrm{pH} 7.4$ ), and $\mathrm{RSL}$ or the synthetic variants were eluted with washing buffer containing $100 \mathrm{mM} \mathrm{D}(+)$-mannose (Carl Roth $\mathrm{GmbH}$, Karlsruhe, Germany). The proteins were dialyzed against $\mathrm{ddH}_{2} \mathrm{O}$ for 5 days at $4{ }^{\circ} \mathrm{C}$, changing water twice a day, lyophilized, and stored at $4{ }^{\circ} \mathrm{C}$ until use.
Intact Protein LC-MS Analysis of RSL Species. Protein solutions were diluted to $10 \mathrm{ng} \mu \mathrm{L}^{-1}$ with water containing $5 \% \mathrm{ACN}$ and $0.1 \% \mathrm{FA}$. Possible protein variations were separated by nano-HPLC (Dionex Ultimate 3000) equipped with a Pepswift precolumn (monolithic, $5 \times$ $0.2 \mathrm{~mm}^{2}$ ) and a ProSwift RP-4H column (monolithic, $100 \mu \mathrm{m} \times 25 \mathrm{~cm}$ ) (all Thermo Fisher Scientific, Vienna, Austria). One microliter of protein sample was injected and concentrated on the enrichment column for $2 \mathrm{~min}$ at a flow rate of $5 \mu \mathrm{L} \mathrm{min}{ }^{-1}$ with $0.1 \%$ formic acid as isocratic solvent. Separation was carried out on the nanocolumn at a flow rate of $1 \mu \mathrm{L} \mathrm{min}{ }^{-1}$ at $37^{\circ} \mathrm{C}$ using the following gradient: solvent $\mathrm{A}$ is $0.1 \%$ formic acid in water and solvent $\mathrm{B}$ acetonitrile containing $0.1 \%$ formic acid: $0-2 \mathrm{~min}, 5 \% \mathrm{~B}$; $2-17 \mathrm{~min}, 5-60 \% \mathrm{~B} ; 17-20 \mathrm{~min}, 60 \% \mathrm{~B}$; 20-20.1 min, 60-5\% B; 20.1-29 min, 5\% B. The maXis II ETD mass spectrometer (Bruker, Bremen, Germany) was operated with the captive spray source in positive mode with following settings: mass range, 300-3000 m/z; $1 \mathrm{~Hz}$; source voltage, $1.6 \mathrm{kV}$; dry gas flow, $3 \mathrm{~L}$ $\min ^{-1} ; 180^{\circ} \mathrm{C}$. The protein mass spectra were deconvoluted by the data analysis software, using the MaxEnt 2 algorithm. The following main parameters were applied: charge carrier, $\mathrm{H}^{+} ; \mathrm{m} / z$ range, min. 800 to max. 2000; minimum instrument resolving power was set to 50000 . For peak detection SNAP algorithm with the following parameters was used: quality factor threshold $0.9, \mathrm{~S} / \mathrm{N}$ threshold 2 , and maximum charge state of 12 .

Amino Acid Sequence Analysis by LC-MS/MS of RSL Species. Twenty micrograms of RSL protein species was reduced with tris(2carboxyethyl)phosphine (TCEP, final $10 \mathrm{mM}$ ) and alkylated with chloroacetamide (final $40 \mathrm{mM}$ ) for $10 \mathrm{~min}$ by shaking at $550 \mathrm{rpm}$ at 95 ${ }^{\circ} \mathrm{C}$. Proteins were digested separately by adding $0.2 \mu \mathrm{g}$ of Promega modified trypsin and shaking overnight at $550 \mathrm{rpm}$ at $37^{\circ} \mathrm{C}$ or adding $0.2 \mu \mathrm{g}$ of chymotrypsin (Promega, Madison, WI) according to the manufacturer's instructions. The resulting peptide solutions were acidified by adding formic acid to a final concentration of $0.1 \%$. Fifty nanograms of the digests was injected and concentrated on the enrichment column (C18, $\left.5 \mu \mathrm{m}, 100 \AA, 5 \times 0.3 \mathrm{~mm}^{2}\right)$ for 2 min using $0.1 \%$ formic acid as isocratic solvent at $5 \mu \mathrm{L} \mathrm{min}{ }^{-1}$ flow rate. The column was then switched in the nanoflow circuit, and the sample was loaded on the Acclaim PepMap RSLC nanocolumn $(\mathrm{C} 18,2 \mu \mathrm{m}, 100 \AA$, $500 \times$ $\left.0.075 \mathrm{~mm}^{2}\right)$ at a flow rate of $250 \mathrm{~nL} \mathrm{m^{-1 }}$ at $60{ }^{\circ} \mathrm{C}$ and separated using the following gradient: solvent $\mathrm{A}$, water, $0.1 \%$ formic acid; solvent $\mathrm{B}$, acetonitrile, $0.1 \%$ formic acid; 0-2 min, 4\% B; 2-90 min, 4-25\% B; 90-95 min, 25-95\% B, 96-110 min, 95\% B; 110-110.1 min, 4\% B; $110.1-125 \mathrm{~min}, 4 \% \mathrm{~B}$. The sample was ionized in the nanospray source equipped with stainless steel emitters (Thermo Fisher Scientific) and analyzed in a Thermo Orbitrap velos pro mass spectrometer in positive ion mode by alternating full scan MS ( $\mathrm{m} / z 300$ to 2000, 60000 resolution) in the ICR cell and MS/MS by CID of the 20 most intense peaks in the ion trap with dynamic exclusion enabled. The LC-MS/MS data were analyzed by searching a homemade database containing all common contaminants with Proteome Discoverer 1.4 (Thermo Fisher Scientific) and Mascot 2.4.1 (MatrixScience, London, UK). Carbamidomethylation on cysteine was entered as fixed and oxidation on methionine and fluorination on tryptophan as variable modification. Detailed search criteria were used as follows: trypsin or chymotrypsin; maximum missed cleavage sites, 2; search mode, MS/MS ion search with decoy database search included; precursor mass tolerance, \pm 10 ppm; product mass tolerance, $\pm 0.7 \mathrm{Da}$; label free quantitation of precursor ions was performed with Proteome Discoverer 1.4. Peptide precursor ion intensities were normalized on total RSL protein intensity and compared for each peptide over the different protein species.

Differential Scanning Fluorimetry (DSF). DSF was performed with a 7500 Real Time PCR System (Applied Biosystems PerkinElmer Corp., Foster City, CA). Protein samples of 3.5-11.0 $\mu \mathrm{M}$ were measured in PBS $\left(9.55 \mathrm{mM} \mathrm{Na}_{2} \mathrm{HPO}_{4}, 136.89 \mathrm{mM} \mathrm{NaCl}, 2.68 \mathrm{mM} \mathrm{KCl}\right.$, $1.47 \mathrm{mM} \mathrm{KH}_{2} \mathrm{PO}_{4}$ ) with $8 \times$ Sypro Orange (Sigma-Aldrich) in the presence $(8 \mu \mathrm{M})$ or absence of $\mathrm{D}-(+)$-mannose (Carl Roth). Melting temperatures of triplicate measurements performed on three different days were analyzed with the Protein Thermal Shift software v1.3 (Applied Biosystems). SigmaPlot (Systat software, San Jose, CA) was used for the statistical analysis of the significance of the generated melting temperatures and for box plot preparation. 
Differential Scanning Calorimetry (DSC). DSC was performed with a VP-DSC (MicroCal, Inc., Northampton, MA). Protein samples were prepared in $20 \mathrm{mM}$ Tris $/ \mathrm{Cl}, 100 \mathrm{mM} \mathrm{NaCl}, 1 \mathrm{mM} \alpha \mathrm{MeFuc}$, $\mathrm{pH}$ 7.5 , with concentrations of $1.5 \mathrm{mg} \mathrm{mL}^{-1}$ for RSL and RSL[5FW] and 1.0 $\mathrm{mg} \mathrm{mL} \mathrm{m}^{-1}$ for $\mathrm{RSL}[4 \mathrm{FW}]$ and $\mathrm{RSL}[7 \mathrm{FW}]$. Measurements were performed at $30 \mathrm{psi}$ pressure and a scan rate of $1{ }^{\circ} \mathrm{C} \mathrm{min}{ }^{-1}$. Data was analyzed with the MicroCal Origin software (VP-DSC version).

Glycan Microarray Analysis. The lectins were biotinylated using the EZ-Link Sulfo-NHS-LC-Biotinylation Kit (Thermo Fisher), according to the manufacturers recommendations. The glycan microarrays contained 317 carbohydrate ligands and were printed as described previously. ${ }^{36}$ The microarray slides were blocked with blocking buffer ( $50 \mathrm{mM}$ ethanolamide in $50 \mathrm{mM}$ borate buffer, $\mathrm{pH} 8.0$ ) for one hour and subsequently thoroughly rinsed with $\mathrm{ddH}_{2} \mathrm{O}$. The biotinylated protein samples were diluted in PLI-P buffer $(0.5 \mathrm{M} \mathrm{NaCl}, 3 \mathrm{mM} \mathrm{KCl}, 1.5 \mathrm{mM}$ $\mathrm{KH}_{2} \mathrm{PO}_{4}, 6.5 \mathrm{mM} \mathrm{Na} \mathrm{HPO}_{4}, 1 \%(\mathrm{w} / \mathrm{v})$ BSA, $1 \%(\mathrm{v} / \mathrm{v})$ Triton-X-100, $\mathrm{pH} 7.4$ ) to a protein concentration of $1 \mu \mathrm{g} \mathrm{mL}^{-1}$ and incubated on the microarray slides in a humidified chamber at $\mathrm{RT}$ with gentle agitation for one hour. After incubation, the protein sample was removed and the slides were washed with PBS buffer $\left(10 \mathrm{mM} \mathrm{Na} \mathrm{HPO}_{4}, 10 \mathrm{mM}\right.$ $\mathrm{NaH}_{2} \mathrm{PO}_{4}, 138 \mathrm{mM} \mathrm{NaCl}, 2.7 \mathrm{mM} \mathrm{KCl}, \mathrm{pH}$ 7.4). The microarray slides were then incubated with cyanine-3 labeled streptavidin (Thermo Fisher) diluted 1:500 in PLI-P buffer for $1 \mathrm{~h}$, as described above. Subsequently, the slides were washed with PBS buffer, rinsed with $\mathrm{ddH}_{2} \mathrm{O}$, and stored in the dark until scanning. Fluorescent measurements were performed using the ScanArray 4000 Microarray Analysis System (PerkinElmer, Waltham, MA). Fluorescence intensities were quantified using the ScanArray Express Microarray Analysis System 4.0 (PerkinElmer) and the data was further analyzed with Microsoft Excel (Microsoft Corporation, Redmond, WA).

Isothermal Titration Calorimetry (ITC). ITC experiments were performed on a MicroCal iTC200 microcalorimeter (Malvern Instruments Ltd., Worcestershire, UK). The experiments were carried out at $25^{\circ} \mathrm{C} . \alpha \mathrm{MeFuc}$ (Tokyo Chemical Industry Europe), HType2, and Le ${ }^{\mathrm{X}}$ tetrasacharides (ELICITYL, Crolles, France), as well as the lyophilized proteins, were dissolved in the same buffer $(20 \mathrm{mM}$ Tris/Cl, $100 \mathrm{mM}$ $\mathrm{NaCl}, \mathrm{pH} 7.5)$. Protein concentrations in the microcalorimeter cell (204 $\mu \mathrm{L}$ ) varied from 0.0476 to $0.0554 \mathrm{mM}$ and between 0.242 and 0.266 $\mathrm{mM}$ for measurements with $\alpha \mathrm{MeFuc} / \mathrm{HType} 2$ and Le $\mathrm{x}^{\mathrm{x}}$, respectively. Twenty injections with $1 \mu \mathrm{L}$ of sugar solutions ( 1 or $1.5 \mathrm{mM}$ of $\alpha \mathrm{MeFuc}$ and HType 2 or $5 \mathrm{mM}$ of Le ${ }^{\mathrm{X}}$ ) were performed at intervals of $120 \mathrm{~s}$ with stirring at $750 \mathrm{rpm}$. The obtained data was integrated and fitted to a theoretical titration curve with Origin software (OriginLab Corporation, Northampton, MA) applying the one-set-of-sites model. The protein concentration was determined using NanoDrop 2000 spectrophotometer (Thermo Fisher Scientific). An extinction coefficient of $43.68 \times 10^{4}$ $\mathrm{M}^{-1} \mathrm{~cm}^{-1}$ was used. For the variants, the concentration was adjusted in the software to obtain the binding site stoichiometry of $n=2$, that is, one inter- and intramonomeric binding site per monomer as confirmed by the crystal structures.

Crystallization and Structure Determination. The three fluorinated RSL samples were dissolved in $20 \mathrm{mM}$ Hepes 7.5 and 150 $\mathrm{mM} \mathrm{NaCl}$ to $8 \mathrm{mg} \mathrm{mL} \mathrm{m}^{-1}$ and cocrystallized with $1 \mathrm{mM} \mathrm{Le}^{\mathrm{X}}$ tetrasaccharide (Ellicityl, Crolles, France). Crystallization screening was performed using the hanging drop vapor diffusion at $19{ }^{\circ} \mathrm{C}$. Diamond shaped crystals were obtained in a few days from solution 1-8 and 1-9 of the Morpheus screen or 1-30 from the Midas screen (Molecular Dimension Ltd., Newmarket, UK). Single crystals were directly mounted in a cryoloop and flash frozen in liquid nitrogen. $\mathrm{RSL}$ [7FW] diffraction data were collected at $100 \mathrm{~K}$ at the European Synchrotron Radiation Facility (Grenoble, France) on BM30A-FIP using an ADSC Q315r detector, while those for $\mathrm{RSL}[4 \mathrm{FW}]$ and RSL $[5 F W]$ were collected at Synchrotron Soleil (Saint Aubin, France) on Proxima 1 using a Pilatus $6 \mathrm{M}$ detector. The data were processed using XDS, ${ }^{40}$ and their quality statistics are summarized in Table S4. All further computing was performed using the CCP4 suite unless otherwise stated. $^{4}$ The RSL[7FW] and RSL[5FW] structures were solved by molecular replacement (MR) using PHASER and the coordinates of chain A from PDB-ID 2BT9 to search for two copies in the asymmetric unit. ${ }^{42}$ After initial rebuilding with ARP/WARP, ${ }^{43}$ the model was refined with restrained maximum likelihood refinement using REFMAC 5.8, ${ }^{44}$ iterated with manual rebuilding in Coot. ${ }^{45}$ The RSL[4FW] structure was also solved by MR using PHASER, but the coordinates of the protein chain A of RSL[5FW] were used as the search model. No rebuilding with ARP/WARP was required. Anisotropic refinement was introduced at the end of the refinement of all structures. Five percent of the observations were set aside for cross-validation analysis, and hydrogen atoms were added in their riding positions and used for geometry and structure-factor calculations. Incorporation of the ligand was performed after inspection of $2 F_{o}-D F_{c}$ weighted maps. The 7FW ligand library was constructed with Acedrg. ${ }^{46}$ Water molecules, introduced first with ARP/WARP and then automatically using Coot, were inspected manually. The model was validated with the wwPDB Validation server (http://wwpdb-validation.wwpdb.org), and the glycans were checked with Privateer. ${ }^{47}$ The coordinates were deposited in the Protein Data Bank under codes 5O7U, 5O7V, and 5O7W, for the structures of RSL[7FW], RSL[5FW], and RSL[4FW], respectively.

We clearly observed the electron density of the carbohydrate ligand in both binding sites of all structures with the exception of chain $\mathrm{A}$ of $\mathrm{RSL}[4 \mathrm{FW}]$, where a glycerol molecule was present in the intramonomeric site. The electron density in the intermonomeric site was of higher quality than in the intramonomeric site in all structures, and the tetrasaccharide was distinctly defined. In contrast, some parts were conformationally disordered in the intramonomeric sites.

Molecular Modeling. The crystal structure of wild-type RSL complexed with $\alpha \mathrm{MeFuc}$ was used as a starting reference to build all models (PDB ID 2BT9). ${ }^{17}$ The fluorinated tryptophans were parametrized for compatibility with the AMBER-ff14SB force field, ${ }^{48}$ using available standard parameters for fluorine for bonding and van der Waals parameters. Fluorination is expected to induce a large modification of the $\pi$ electron density on the indole ring. ${ }^{14}$ Therefore we performed quantum chemistry calculations in order to obtain representative atomic charges for each fluorinated tryptophan. RESP charges ${ }^{49}$ were calculated following the recommended setup of the PyRED server ${ }^{50}$ (http://upjv.q4md-forcefieldtools.org/REDServerDevelopment/). The atomic charges and modified parameters were included in Amber Tools to prepare the topology files of the different systems. Molecular dynamics simulations were carried out using the pmemd module of the AMBER12 code (http://ambermd.org). The AMBER-ff14SB ${ }^{48}$ and GLYCAM06-j ${ }^{51}$ force fields were used for protein and saccharides, respectively, together with the TIP3 water model. ${ }^{52}$ The protonation states of titratable residues were assigned using the $\mathrm{H}+$ + web server (http://biophysics.cs.vt.edu/H++). Standard protonation states were observed for each RSL variant. Short-range van der Waals interactions were switched to zero at a cutoff distance of $8 \AA$. The longrange electrostatic interactions were computed by means of the particle mesh Ewald (PME) method ${ }^{53}$ using a real-space cutoff of $8 \AA$. The SHAKE algorithm was applied to constrain bonds involving hydrogen atoms, and thus an integration time step of $2 \mathrm{fs}$ could be used. The temperature was maintained at $300 \mathrm{~K}$ using the Langevin thermostat with a collision frequency of $2 \mathrm{ps}^{-1}$. A length of $500 \mathrm{~ns}$ of NpT simulation was performed for each RSL variant. The MD trajectories were postprocessed to compute free energies of binding using the MMPBSA.py program. ${ }^{35}$ The intramonomeric binding site of chain A complexed with $\alpha$-L-Me-fucoside was used to make the calculations. The free energy of binding was computed for each RSL variant using the Poisson-Boltzmann surface area (PBSA) framework combined with normal modes analysis. Due to computational cost of the PoissonBoltzmann method, the energy decomposition per residue was performed from generalized Born surface area (GBSA) calculations. ${ }^{35}$

\section{ASSOCIATED CONTENT}

\section{Supporting Information}

The Supporting Information is available free of charge on the ACS Publications website at DOI: 10.1021/acschembio.8b00377.

Sequences of RSL and primers used, quantification of FW incorporation into RSL, affinity constants and thermody- 
namics parameters, data collection and refinement statistics for fluorinated RSL co-crystallized with $\mathrm{Le}^{\mathrm{X}}$ tetrasaccharide, conformation of the $\mathrm{Le}^{\mathrm{X}}$ tetrasaccharide in each binding site, atomic charges used for Amber parameterization of the fluorinated tryptophan residues, expression and purification of fluorotryptophan-containing RSL variants, mass analysis of the fluorinated RSL variants, quantification of the incorporation of FW at individual positions, melting temperatures of RSL and fluorinated variants, ITC data of the interaction of RSL and fluorinated variants with $\alpha \mathrm{MeFuc}$ and the two tetrasaccharides, electron density in the binding sites of the variant lectins complexed with the tetrasaccharide $\mathrm{Le}^{\mathrm{X}}$, superimposition of X-ray crystal structure and averaged one from $\mathrm{MD}$ calculations in the intermonomeric binding site of fucose in RSL[7FW], image analysis of glycan microarrays with RSL and the FW-containing variants, and interaction of the RSL and variants with the eight selected oligosaccharides (PDF)

\section{AUTHOR INFORMATION}

\section{Corresponding Authors}

*B.W. E-mail: birgit.wiltschi@acib.at.

*A.I. E-mail: anne.imberty@cermav.cnrs.fr.

ORCID $\odot$

Mickael Lelimousin: 0000-0002-4547-0132

Annabelle Varrot: 0000-0001-6667-8162

Ola Blixt: 0000-0003-4143-6276

Ruth Birner-Gruenberger: 0000-0003-3950-0312

Birgit Wiltschi: 0000-0001-5230-0951

\section{Funding}

The authors acknowledge support by the Austrian Science Fund (FWF) project number I 1708-B22 in the framework of the EU ERASynBio project SynGlycTis as well as by the FWF project number W901 (DK Molecular Enzymology). This work has been supported by the Austrian BMWFW, BMVIT, SFG, Standortagentur Tirol, Government of Lower Austria, and ZIT through the Austrian FFG-COMET-Funding Program (grant number 282482) and the French ANR for Glyco@Alps (ANR15-IDEX-02) and Labex ARCANE (ANR-11-LABX-003).

\section{Notes}

The authors declare no competing financial interest.

\section{ACKNOWLEDGMENTS}

We are grateful to K. Lohner and A. Zenz for excellent assistance with DSC measurements and analysis and to P. Megusar and L. Gajdos for crystallization trials. We are grateful to Synchrotron SOLEIL (Saint Aubin, France) and ESRF (Grenoble, France) for access and technical support with beamlines PROXIMA1 and BM30A-FIP, respectively. MD calculations were partially performed on the CECIC platform of ICMG.

\section{ABBREVIATIONS}

RSL, Ralstonia solanacearum lectin; 4FW, 4-fluorotryptophan; 5FW, 5-fluorotryptophan; 6FW, 6-fluorotryptophan; 7FW, 7fluorotryptophan; $\alpha$ MeFuc, $\alpha$-L-methyl fucopyranoside; HType2, blood group $\mathrm{H}$ type 2 antigen; Le ${ }^{\mathrm{X}}$, lewis X

\section{REFERENCES}

(1) Varki, A., Cummings, R. D., Esko, J. D., Freeze, H. H., Stanley, P., Bertozzi, C. R., Hart, G. W., and Etzler, M. E. (2009) Essentials of
Glycobiology, 2nd ed., Cold Spring Harbor Laboratory Press, Cold Spring Harbor, NY.

(2) Arnaud, J., Audfray, A., and Imberty, A. (2013) Binding sugars: from natural lectins to synthetic receptors and engineered neolectins. Chem. Soc. Rev. 42, 4798-4813.

(3) Yoo, T. H., Link, A. J., and Tirrell, D. A. (2007) Evolution of a fluorinated green fluorescent protein. Proc. Natl. Acad. Sci. U. S. A. 104, 13887-13890.

(4) Hyun Bae, J., Rubini, M., Jung, G., Wiegand, G., Seifert, M. H. J., Azim, M. K., Kim, J.-S., Zumbusch, A., Holak, T. A., Moroder, L., Huber, R., and Budisa, N. (2003) Expansion of the genetic code enables design of a novel "gold" class of green fluorescent proteins. J. Mol. Biol. 328, $1071-1081$.

(5) Dieterich, D. C., Link, A. J., Graumann, J., Tirrell, D. A., and Schuman, E. M. (2006) Selective identification of newly synthesized proteins in mammalian cells using bioorthogonal noncanonical amino acid tagging (BONCAT). Proc. Natl. Acad. Sci. U. S. A. 103, 9482-9487.

(6) Beatty, K. E., and Tirrell, D. A. (2008) Two-color labeling of temporally defined protein populations in mammalian cells. Bioorg. Med. Chem. Lett. 18, 5995-5999.

(7) Zhang, K., Sugawara, A., and Tirrell, D. A. (2009) Generation of surface-bound multicomponent protein gradients. ChemBioChem 10, 2617-2619.

(8) Prasuhn, D. E., Jr., Singh, P., Strable, E., Brown, S., Manchester, M., and Finn, M. G. (2008) Plasma clearance of bacteriophage $\mathrm{Q} \beta$ particles as a function of surface charge. J. Am. Chem. Soc. 130, 1328-1334.

(9) Lang, K., and Chin, J. W. (2014) Cellular incorporation of unnatural amino acids and bioorthogonal labeling of proteins. Chem. Rev. 114, 4764-4806.

(10) Dumas, A., Lercher, L., Spicer, C. D., and Davis, B. G. (2015) Designing logical codon reassignment - Expanding the chemistry in biology. Chem. Sci. 6, 50-69.

(11) Ravikumar, Y., Nadarajan, S. P., Hyeon Yoo, T., Lee, C.-S., and Yun, H. (2015) Incorporating unnatural amino acids to engineer biocatalysts for industrial bioprocess applications. Biotechnol. J. 10, $1862-1876$

(12) Ravikumar, Y., Nadarajan, S. P., Hyeon Yoo, T., Lee, C.-s., and Yun, H. (2015) Unnatural amino acid mutagenesis-based enzyme engineering. Trends Biotechnol. 33, 462-470.

(13) Salwiczek, M., Nyakatura, E. K., Gerling, U. I. M., Ye, S., and Koksch, B. (2012) Fluorinated amino acids: compatibility with native protein structures and effects on protein-protein interactions. Chem. Soc. Rev. 41, 2135-2171.

(14) Katragadda, M., Magotti, P., Sfyroera, G., and Lambris, J. D. (2006) Hydrophobic effect and hydrogen bonds account for the improved activity of a complement inhibitor, compstatin. J. Med. Chem. 49, 4616-4622.

(15) Luck, L. A., and Falke, J. J. (1991) 19F NMR studies of the Dgalactose chemosensory receptor. 1. Sugar binding yields a global structural change. Biochemistry 30, 4248-4256.

(16) Chavez, M. I., Andreu, C., Vidal, P., Aboitiz, N., Freire, F., Groves, P., Asensio, J. L., Asensio, G., Muraki, M., Canada, F. J., and JimenezBarbero, J. (2005) On the importance of carbohydrate-aromatic interactions for the molecular recognition of oligosaccharides by proteins: NMR studies of the structure and binding affinity of AcAMP2-like peptides with non-natural naphthyl and fluoroaromatic residues. Chem. - Eur. J. 11, 7060-7074.

(17) Kostlanova, N., Mitchell, E. P., Lortat-Jacob, H., Oscarson, S., Lahmann, M., Gilboa-Garber, N., Chambat, G., Wimmerova, M., and Imberty, A. (2005) The fucose-binding lectin from Ralstonia solanacearum: A new type of $\beta$-propeller architecture formed by oligomerization and interacting with fucoside, fucosyllactose, and plant xyloglucan,. J. Biol. Chem. 280, 27839-27849.

(18) Mishra, S. K., Adam, J., Wimmerova, M., and Koca, J. (2012) In silico mutagenesis and docking study of Ralstonia solanacearum RSL lectin: performance of docking software to predict saccharide binding. J. Chem. Inf. Model. 52, 1250-1261.

(19) Wimmerova, M., Kozmon, S., Necasova, I., Mishra, S. K., Komarek, J., and Koca, J. (2012) Stacking interactions between 
carbohydrate and protein quantified by combination of theoretical and experimental methods. PLoS One 7, No. e46032.

(20) Asensio, J. L., Arda, A., Canada, F. J., and Jimenez-Barbero, J. (2013) Carbohydrate-aromatic interactions. Acc. Chem. Res. 46, 946954.

(21) Hudson, K. L., Bartlett, G. J., Diehl, R. C., Agirre, J., Gallagher, T., Kiessling, L. L., and Woolfson, D. N. (2015) Carbohydrate-aromatic interactions in proteins. J. Am. Chem. Soc. 137, 15152-15160.

(22) Topin, J., Lelimousin, M., Arnaud, J., Audfray, A., Perez, S., Varrot, A., and Imberty, A. (2016) The hidden conformation of Lewis $\mathrm{x}$, a human histo-blood group antigen, is a determinant for recognition by pathogen lectins,. ACS Chem. Biol. 11, 2011-2020.

(23) Wiltschi, B. (2012) Expressed protein modifications: Making synthetic proteins. Methods Mol. Biol. 813, 211-225.

(24) Lepthien, S., Hoesl, M. G., Merkel, L., and Budisa, N. (2008) Azatryptophans endow proteins with intrinsic blue fluorescence. Proc. Natl. Acad. Sci. U. S. A. 105, 16095-16100.

(25) Fleischmann, R. D., Adams, M. D., White, O., Clayton, R. A. Kirkness, E. F., Kerlavage, A. R., Bult, C. J., Tomb, J. F., Dougherty, B. A., Merrick, J. M., et al. (1995) Whole-genome random sequencing and assembly of Haemophilus influenzae Rd. Science 269, 496-512.

(26) Sloan, M. J., and Phillips, R. S. (1992) Enzymatic synthesis of azaL-tryptophans: The preparation of 5- and 6-aza-L-tryptophan,. Bioorg. Med. Chem. Lett. 2, 1053-1056.

(27) Lee, M. S., and Phillips, R. S. (1992) Enzymatic synthesis of chloro-L-tryptophans. Bioorg. Med. Chem. Lett. 2, 1563-1564.

(28) Phillips, R. S. (2004) Synthetic applications of tryptophan synthase. Tetrahedron: Asymmetry 15, 2787-2792.

(29) Holmgren, S. K., Taylor, K. M., Bretscher, L. E., and Raines, R. T. (1998) Code for collagen's stability deciphered. Nature 392, 666-667. (30) Montclare, J. K., Son, S., Clark, G. A., Kumar, K., and Tirrell, D. A. (2009) Biosynthesis and stability of coiled-coil peptides containing (2S,4R)-5,5,5-trifluoroleucine and (2S,4S)-5,5,5-trifluoroleucine. ChemBioChem 10, 84-86.

(31) Shoulders, M. D., Satyshur, K. A., Forest, K. T., and Raines, R. T. (2010) Stereoelectronic and steric effects in side chains preorganize a protein main chain. Proc. Natl. Acad. Sci. U. S. A. 107, 559-564.

(32) Aeschbacher, T., Zierke, M., Smiesko, M., Collot, M., Mallet, J. M., Ernst, B., Allain, F. H., and Schubert, M. (2017) A secondary structure element present in a wide range of fucosylated glycoepitopes. Chem. Eur. J. 23, 11598-11610.

(33) Dunitz, J. D., and Taylor, R. (1997) Organic Fluorine Hardly Ever Accepts Hydrogen Bonds. Chem. - Eur. J. 3, 89-98.

(34) Samsonov, S. A., Salwiczek, M., Anders, G., Koksch, B., and Pisabarro, M. T. (2009) Fluorine in protein environments: a QM and MD study. J. Phys. Chem. B 113, 16400-16408.

(35) Miller, B. R., 3rd, McGee, T. D., Jr., Swails, J. M., Homeyer, N., Gohlke, H., and Roitberg, A. E. (2012) MMPBSA.py: An Efficient Program for End-State Free Energy Calculations. J. Chem. Theory Comput. 8, 3314-3321.

(36) Frederiksen, R. F., Yoshimura, Y., Storgaard, B. G., Paspaliari, D. K., Petersen, B. O., Chen, K., Larsen, T., Duus, J. O., Ingmer, H., Bovin, N. V., Westerlind, U., Blixt, O., Palcic, M. M., and Leisner, J. J. (2015) A diverse range of bacterial and eukaryotic chitinases hydrolyzes the LacNAc (Galbeta1-4GlcNAc) and LacdiNAc (GalNAcbeta14GlcNAc) motifs found on vertebrate and insect cells,. J. Biol. Chem. 290, 5354-5366.

(37) Audfray, A., Claudinon, J., Abounit, S., Ruvoën-Clouet, N., Larson, G., Smith, D. F., Wimmerová, M., Le Pendu, J., Römer, W., Varrot, A., and Imberty, A. (2012) The fucose-binding lectin from opportunistic pathogen Burkholderia ambifaria binds to both plant and human oligosaccharidic epitopes,. J. Biol. Chem. 287, 4335-4347.

(38) Chatterjee, A., Xiao, H., Yang, P.-Y., Soundararajan, G., and Schultz, P. G. (2013) A tryptophanyl-tRNA synthetase/tRNA pair for unnatural amino acid mutagenesis in E. coli. Angew. Chem., Int. Ed. 52, 5106-5109.

(39) Gibson, D. G., Young, L., Chuang, R.-Y., Venter, J. C., Hutchison, C. A., and Smith, H. O. (2009) Enzymatic assembly of DNA molecules up to several hundred kilobases. Nat. Methods 6, 343-345.
(40) Kabsch, W. (2010) Xds. Acta Crystallogr., Sect. D: Biol. Crystallogr. $66,125-132$.

(41) Winn, M. D., Ballard, C. C., Cowtan, K. D., Dodson, E. J., Emsley, P., Evans, P. R., Keegan, R. M., Krissinel, E. B., Leslie, A. G., McCoy, A., McNicholas, S. J., Murshudov, G. N., Pannu, N. S., Potterton, E. A., Powell, H. R., Read, R. J., Vagin, A., and Wilson, K. S. (2011) Overview of the CCP4 suite and current developments. Acta Crystallogr., Sect. D: Biol. Crystallogr. 67, 235-242.

(42) McCoy, A. J., Grosse-Kunstleve, R. W., Adams, P. D., Winn, M. D., Storoni, L. C., and Read, R. J. (2007) Phaser crystallographic software. J. Appl. Crystallogr. 40, 658-674.

(43) Langer, G., Cohen, S. X., Lamzin, V. S., and Perrakis, A. (2008) Automated macromolecular model building for X-ray crystallography using ARP/wARP version 7. Nat. Protoc. 3, 1171-1179.

(44) Murshudov, G. N., Skubak, P., Lebedev, A. A., Pannu, N. S., Steiner, R. A., Nicholls, R. A., Winn, M. D., Long, F., and Vagin, A. A. (2011) REFMAC5 for the refinement of macromolecular crystal structures. Acta Crystallogr., Sect. D: Biol. Crystallogr. 67, 355-367.

(45) Emsley, P., Lohkamp, B., Scott, W. G., and Cowtan, K. (2010) Features and development of Coot. Acta Crystallogr., Sect. D: Biol. Crystallogr. 66, 486-501.

(46) Long, F., Nicholls, R. A., Emsley, P., Gražulis, S., Merkys, A., Vaitkus, A., and Murshudov, G. N. (2017) AceDRG: a stereochemical description generator for ligands. Acta Crystallogr., Sect. D: Biol. Crystallogr. 73, 112-122.

(47) Agirre, J., Iglesias-Fernandez, J., Rovira, C., Davies, G. J., Wilson, K. S., and Cowtan, K. D. (2015) Privateer: software for the conformational validation of carbohydrate structures. Nat. Struct. Mol. Biol. 22, 833-834.

(48) Maier, J. A., Martinez, C., Kasavajhala, K., Wickstrom, L., Hauser, K. E., and Simmerling, C. (2015) ff14SB: Improving the Accuracy of Protein Side Chain and Backbone Parameters from ff99SB. J. Chem. Theory Comput. 11, 3696-3713.

(49) Bayly, C. I., Cieplak, P., Cornell, W., and Kollman, P. A. (1993) A well-behaved electrostatic potential based method using charge restraints for deriving atomic charges: the RESP model,. J. Phys. Chem. 97, 10269-10280.

(50) Vanquelef, E., Simon, S., Marquant, G., Garcia, E., Klimerak, G., Delepine, J. C., Cieplak, P., and Dupradeau, F. Y. (2011) R.E.D. Server: a web service for deriving RESP and ESP charges and building force field libraries for new molecules and molecular fragments. Nucleic Acids Res. 39, W511-W517.

(51) Kirschner, K. N., Yongye, A. B., Tschampel, S. M., GonzalezOuteirino, J., Daniels, C. R., Foley, B. L., and Woods, R. J. (2008) GLYCAM06: a generalizable biomolecular force field. Carbohydrates. J. Comput. Chem. 29, 622-655.

(52) Jorgensen, W. L., Chandrasekhar, J., Madura, J. D., Impey, R. W., and Klein, M. L. (1983) Comparison of simple potential functions for simulating liquid water. J. Chem. Phys. 79, 926-935.

(53) Darden, T., York, D., and Pedersen, L. (1993) Particle mesh Ewald: An N.log(N) method for Ewald sums in large systems. J. Chem. Phys. 98, 10089-10092. 